\title{
IDENTIFICACIÓN DEL PATRIMONIO CULTURAL PARA EL DESARROLLO TURÍSTICO SUSTENTABLE. CASO COMONFORT, MÉXICO
}

\author{
Francisco Javier González Rojas \\ Universidad de Guanajuato \\ pacroog@gmail.com

\section{Mónica Isabel Mejía Rocha} \\ Universidad de Guanajuato \\ monica_mr47@hotmail.com
}

\section{RESUMEN}

El siguiente trabajo, es una revisión monográfica y exploratoria sobre el potencial cultural de la ciudad de Comonfort, Guanajuato, basada en los modelos de sustentabilidad para destinaciones turísticas. Se obtiene un catálogo adecuado para generar ideas sobre el desarrollo para los residentes locales a través del turismo cultural y futuras designaciones. Contempla datos históricos del municipio que se recogieron de historias y obras contadas por su gente, que son los principales promotores de datos para la futura generación de estrategias en pro de la ciudad. Se revisó información de las instituciones de turismo y organizaciones gubernamentales para desarrollar un marco teórico y dar las posibles conclusiones y recomendaciones acerca del potencial cultural. Al identificar dicho patrimonio, se logró integrar un inventario sustancial de elementos culturales propios del destino. Este inventario puede contribuir en la planeación de este destino hacia un desarrollo turístico sustentable.

Palabras Clave: Patrimonio Cultural, desarrollo turístico, identificación, sustentabilidad, Comonfort. 


\title{
CULTURAL HERITAGE FOR SUSTAINABLE TOURISM. COMONFORT CASE, MEXICO.
}

\author{
Francisco Javier González Rojas \\ Universidad de Guanajuato \\ pacroog@gmail.com \\ Mónica Isabel Mejía Rocha \\ Universidad de Guanajuato \\ monica_mr47@hotmail.com
}

\begin{abstract}
The following monograph is based on both, an exploratory review of the cultural potential of the city of Comonfort (Guanajuato), as well as on models of sustainability for tourist destinations. As a result, a catalog suitable to generate ideas for local development through cultural tourism and future designations it is obtained. It includes historical data that were collected in the municipality from stories told by local people. Information of tourism institutions and government organizations were also reviewed in order to develop a theoretical framework and propose possible conclusions and recommendations about the cultural potential of the city. By identifying this heritage, a substantial inventory of cultural elements for the destination was developed. This inventory can help in planning the destination towards sustainable tourism development.
\end{abstract}

Key words: Cultural heritage, tourism development, identification, sustainability, Comonfort. 


\section{INTRODUCCIÓN}

El siguiente trabajo reúne las características de un destino en surgimiento, plasma los principales conceptos para delimitar funciones específicas de los destinos partiendo de los procesos de Sostenibilidad y Sustentabilidad. Un proceso es sostenible cuando ha desarrollado la capacidad para producir indefinidamente a un ritmo en el cual no agota los recursos que utiliza y que necesita para funcionar y no produce más contaminantes de los que puede absorber su entorno. El desarrollo sustentable hace referencia a la capacidad que haya desarrollado el sistema humano para satisfacer las necesidades de las generaciones actuales sin comprometer los recursos y oportunidades para el crecimiento y desarrollo de las generaciones futuras. Sustentabilidad es la habilidad de lograr una prosperidad económica sostenida en el tiempo protegiendo al mismo tiempo los sistemas naturales del planeta y proveyendo una alta calidad de vida para las personas. (Calvante, 2007). Se han revisado conceptos y su relación con el turismo de manera de poner crear ideas acertadas en la revisión de literatura. La metodología ha sido creada de acuerdo a etapas exploratorias donde se hizo el primer contacto con el local para generar suplentes hacia la actividad turística de Comonfort Guanajuato, se ha basado en el Modelo de Competitividad y Sostenibilidad del destino de Ritchie \& Crouch (2003), como estándar de evaluación. Para efectos del trabajo y estructura de metodología se han revisado literatura y documentos de los principales organismos mundiales como actores de diseño y gestión para el turismo, integrando a los federales y en último momento los municipales guiados en el caso de estudio. Lo anterior, a fin de obtener un catálogo preliminar de atractivos del municipio de Comonfort, Guanajuato nos documentaremos en campo por medio de encuestas, herramientas fotográficas, inclusión en redes sociales, recorridos, archivos históricos, obras de cronistas y relatos como proceso de investigación exploratoria.

Se ha puesto a revisión el destino mediante una previa caracterización de recursos y carencias para dar paso a las etapas de exploración, el caso de estudio han sido los siete barrios principales: Camacho, Barrio de la Palma, Barrio de la Candelaria, Barrio de Montecillo, Barrio de los Remedios, Barrio de la Rinconada y Barrio de San Agustín, donde se categorizan algunos atractivos de los principales poblados: Empalme Escobedo, Rancho de Landin, Rancho de las Palmillas de San Juan, Hacienda la Cantera, y Rancho Vallejito, Pueblo de Jalpilla, Soria, Rancho de Dondiego, Neutla, Orduña, Rancho de delgado y Ranchito de delgado, Rancho la Laguna, Ojo de Agua de García, El picacho, Rancho la Asunción, Las Pomas, El Puertecito y Hacienda de Carrera tomados de (Franco, 2015). Donde se recoge información del Chamacuero y se da una idea del alto potencial histórico y cultural que puede imprimir a la oferta turística del estado de Guanajuato, el objetivo de nuestra investigación se cumple con la obtención y retroalimentación de un catálogo de atractivos culturales como activos materiales e inmateriales, artesanías y gastronomía tomando la idea de Ritchie \& Crouch se potencializa desde la imagen del destino para dar 
una previa propuesta de desarrollo en cuestión de este factor para potencializar destino. Se ha integrado un catálogo tomado de (Carracedo, 2016) cronista de la ciudad, pero también se han integrado otros elementos recogidos de las etapas y sondeos con el local, visto este como el principal promotor de destino y precursor de actividades endémicas y efímeras.

\section{ANTECEDENTES}

De acuerdo con cifras de la OMT, el turismo internacional creció 5.1 por ciento en los primeros cuatro meses de este 2016. El crecimiento turístico de México entre el primer cuatrimestre de 2012 y el de 2016 fue de 45.8 por ciento. La actividad turística en México creció a casi el doble de la tasa a nivel mundial, en el primer cuatrimestre de 2016 (SECTUR, 2016)1. México es uno de los mercados emergentes más activos en el escenario internacional. Fruto de más de 3.000 años de civilizaciones diversas, tiene una gran riqueza cultural. Con más de 46.000 sitios arqueológicos, 108.000 monumentos históricos y 1.200 museos, es una de las naciones con mayor cantidad de sitios designados como Patrimonio de la Humanidad por la UNESCO (27). Asimismo, ocupa el tercer lugar entre los países con mayor diversidad lingüística y es un destino ideal para admirar la influencia del pasado indígena y la preservación de tradiciones ancestrales. (OMT, 2016)2. El importante crecimiento económico del sector turístico ha sido, en general, poco planificado, y en ocasiones ha provocado efectos negativos en las economías y en la población receptora, originando una importante degradación ambiental e incluso también social y cultural. Esto suele ocurrir cuando el turismo no es originado ni gestionado por la propia población de la región receptora. (AMYCOS, 2010)4. Para efectos de las comunidades hacia esta derrama económica y principales beneficios, el código ético para el turismo (ONU, 2001) en sus artículos 4 y 5 plantea que los recursos turísticos pertenecen al patrimonio común de la humanidad. Las comunidades en cuyo territorio se encuentran tienen con respecto a ellos derechos y obligaciones particulares. Las políticas y actividades turísticas se llevarán a cabo con respeto al patrimonio artístico, arqueológico y cultural, que deben proteger y transmitir a las generaciones futuras. La actividad turística se organizará de modo que permita la supervivencia y el florecimiento de la producción cultural y artesanal tradicional, así como del folklore, y que no conduzca a su normalización y empobrecimiento.

El turismo hoy en día se encuentra ampliamente ligado al desarrollo y abarca un número creciente de nuevos destinos. Este dinamismo ha originado que el turismo se convierta en el elemento clave para el progreso socio-económico (Ruiz, 2008)5. Ante los impactos negativos del turismo aparece la necesidad de desarrollar un turismo más responsable con el entorno sociocultural y medioambiental. A mediados de los 90 's, ante el turismo de masas, empieza a surgir el turismo alternativo y poco a poco aparecen términos como "ecoturismo", "turismo responsable", "turismo comunitario" o "turismo sustentable". En este último ha ganado más peso el aspecto ambiental, pero 
para efectos de un turismo responsable debe lograr una equidad con los demás aspectos integrados. El desarrollo turístico sustentable significa que los lugares vayan creciendo de forma ordenada, con planeación, donde las inversiones se canalicen de tal manera que se vayan sumando y que en el largo plazo sigan siendo exitosos. (Sánchez, 2016)6. Los Objetivos de Desarrollo Sostenible (ODS) ofrecen una visión de un mundo más justo, más próspero, pacífico y sostenible, en el que nadie es dejado atrás, estos 17 puntos fueron decretados por las Naciones Unidas y son parte de la agenda 2030, Considerando que la comunidad internacional ha concentrado sus esfuerzos en un modelo de desarrollo sostenible con la adopción de una agenda de desarrollo que permita a los Estados tomar acciones concretas encaminadas a lograr un equilibrio entre las dimensiones sociales, ambientales y económicas del desarrollo sostenible. Como base para el turismo responsable y gestionado se deberán de considerar estos objetivos a fin de proponer el desarrollo sustentable para las comunidades y los destinos turísticos, Comonfort siendo un destino en vías de desarrollo pude ejecutar en inicios estos elementos y características. Centrados en sus atractivos culturales tangibles e intangibles se pueden generar ideas hacia el potencial de destino.

\section{METODOLOGÍA}

Este proceso se inició con la adecuada formulación de un área de oportunidad hacia el municipio de Comonfort como desarrollo turístico en crecimiento, revisión de la bibliografía pertinente, así como la aplicación de técnicas de investigación. Este trabajo de tipo monográfico, análisis y reflexión descriptiva tiene como finalidad identificar, determinar y caracterizar los elementos patrimoniales propios del municipio de Comonfort Guanajuato susceptibles a ser desarrollados como atractivos turísticos que permitan potenciar el desarrollo turístico sustentable en este municipio.

\section{MARCO DE REFERENCIA}

\section{Sostenibilidad y Competitividad}

La sostenibilidad se ha convertido en uno de los principales valores del cambio de paradigma en el actual modelo de desarrollo turístico y, por supuesto, es un factor clave para la competitividad de cualquier destino. El turismo es una actividad económica que depende, en buena medida, de la existencia en el destino de atractivos naturales y culturales, lo que implica que sostenibilidad y competitividad sean dos conceptos muy relacionados en la gestión de los destinos turísticos. La gestión de la sostenibilidad tiene que ver con la planificación y gestión del crecimiento, el uso racional del territorio, el control de los recursos frágiles, y con políticas dirigidas a lograr la minimización de los posibles impactos negativos y el mejor aprovechamiento de las oportunidades de negocio y empleo por parte de la población local para favorecer un reparto equitativo de los beneficios. (Pulido, 2010)8. Por su parte la competitividad es un requisito fundamental para lograr beneficios 
económicos, además de que, con la calidad ambiental, que se requiere en todo espacio de ocio, tiene que ver con la capacidad de los agentes del destino para proteger y gestionar los atractivos turísticos, y de organizarse para estructurar y distribuir con éxito productos diferenciados con valor añadido. De acuerdo con OMT el concepto de sostenibilidad está ligado a tres factores importantes: calidad, continuidad y equilibrio. De manera que, el turismo sostenible es definido como un modelo de desarrollo económico diseñado para: Mejorar la calidad de vida de la población local, gente que viva y trabaje en el destino turístico. Provee mayor calidad de experiencia para el visitante. Mantiene la calidad del medio ambiente, del que la población local y los visitantes dependen. Consecución de mayores niveles de rentabilidad económica de la actividad turística para los residentes locales y asegura la obtención de beneficios por parte de los empresarios turísticos. Es decir, ha de procurarse que el negocio turístico sostenible sea rentable, de lo contrario los empresarios olvidarán el compromiso de sostenibilidad y altearán el equilibrio.

La sostenibilidad no es un objeto, ni una estrategia, se trata de un nuevo desafió en el actual modelo de desarrollo turístico, de manera que perfile un nuevo escenario en las relaciones entre turismo y medio ambiente, entendido este en un sentido mucho más amplio que el tradicionalmente se concibe al asociarlo a la idea exclusiva de recursos naturales. (Pulido, 2010). Hay que identificar, por tanto, el turismo sostenible con las ideas de globalidad, multidimensionalidad e integralidad, de manera que el turismo sostenible no se alcanzara más que como resultado de un proceso de cambio en el que se tengan en cuenta diferentes dimensiones: ecológica, sociocultural y económica. La sostenibilidad es un elemento clave para la competitividad de un destino turístico, en la medida en que se garantiza un nuevo escenario, no sustentado sobre los parámetros habituales de crecimiento cuantitativo de la demanda turística, que asegura la preservación del medio ambiente la cultura local, que garantiza la participación de la población, tanto en el proceso de desarrollo como en la apropiación de beneficios, y que favorece una oferta turística de calidad, condiciones indispensables para mantener la competitividad.

\section{Turismo}

En (Blasco, 2011)10 se afirma que en general todo el mundo es turista potencial. Para dar el paso definitivo a poder convertirse en turista, es necesario que se cumplan dos condiciones: voluntad y posibilidad. La primera se refiere al deseo o curiosidad por viajar y conocer otros lugares, otras gentes, otras culturas. Sería meritorio, que existiera un deseo de involucrarse en la cultura del lugar de destino. Es suficiente que haya curiosidad, y esta es innata al ser humano y por tanto ha existido siempre. Los descubridores de nuevas tierras ayudaron a la humanidad a conocer su entorno físico embarcándose en auténticas hazañas que dieron como resultado el conocimiento de otras tierras y culturas. La posibilidad tiene un significado múltiple. Desde la perspectiva política, se refiere a la capacidad que tiene un ciudadano para moverse libremente por 
dentro o fuera de las fronteras de su país, pues no todos los estados permiten o facilitan la libertad de movimiento, y por tanto están restringiendo el turismo, esta también se refiere a la capacidad de ahorro y por tanto de gasto de ese excedente en ocio. El turismo beneficia a muchos países, regiones y comunidades, pero también tiene grandes impactos socioculturales y en el medio ambiente. Esta actividad requiere de un gran consumo de energía para el traslado de los turistas, quienes tienen consumos relativamente altos en los lugares que visitan, y ese perjudica sobre todo a países en desarrollo y regiones sin los medios para proteger los recursos naturales y ecosistemas de las presiones del turismo de masas. Esta actividad puede dañar a los propios atractivos turísticos, lo cual representa una amenaza para esta actividad. (Velarde 2015, en Neto 2003)11. El binomio cultura y turismo constituye un eje fundamental en las propuestas, relativamente recientes, realizadas en México acerca de la promoción del turismo en escenarios pintorescos, típicos, pequeños y representativos de la riqueza cultural del país; tal empresa pone en juego conceptos como cultura, tradición, identidad y magia en escenarios diferenciados de las payas y las grandes urbes; conceptos que se relacionan entre si y que dotan de atributos particulares al lugar. Como ejemplo está el Programa Pueblos Mágicos, que promueve tales categorías, mismas que vale la pena analizar. Como en otros países al abordar el tema de la cultura, en México es pertinente considerar el término de "diversidad biocultural" pues en el territorio nacional hay una gran diversidad de grupos culturales en estrecha interacción con ecosistemas que poseen una gran variedad biológica (Saldaña, en Boege, 2008). La Cultura se define "como el conjunto de los rasgos distintivos, espirituales y materiales, intelectuales y afectivos que caracterizan a una sociedad o un grupo social. Ella engloba, además de las artes y las letras, los modos de vida, los derechos fundamentales al ser humano, los sistemas de valores, las tradiciones y las creencias". La cultura se manifiesta en la arquitectura, la música, la escritura, el lenguaje; en el modo de celebrar una fiesta y sus motivaciones; en la forma de vestir, en las danzas y bailes tradicionales, y en técnicas originarias y particulares de cultivos o de elaboración de platillos. (CONACULTA, 2015)15. Actualmente en la república mexicana hay 111 pueblos mágicos, el programa muestra una serie de riesgos y contradicciones. El programa plantea ser un reconocimiento a quienes habitan esos hermosos lugares de la geografía mexicana y han sabido guardar para todos, la riqueza cultural e histórica que encierran. Los objetivos del programa pueblos mágicos tienen alcances muy amplios, resaltar el valor turístico de las localidades en el interior del país para estructurar una oferta turística innovadora y original, que atienda una demanda naciente de cultura, tradiciones, aventura y deporte extremo en escenarios naturales, o la simple, pero única cotidianidad de la vida rural. (Saldaña, 2014). Un pueblo mágico es una localidad que tiene atributos simbólicos, leyendas, historia, hechos trascendentes, cotidianidad, en fin, magia que emana de cada una de sus manifestaciones socioculturales, y que significan hoy en día una gran oportunidad para el aprovechamiento turístico, necesidad de conjuntar esfuerzos para convertirlos en detonadores de la economía local y regional. El turismo y el flujo de visitantes, 
produce resultados sorprendentes en comunidades de gran fuerza cultural y entornos urbanos y naturales de gran impacto (SECTUR, 2014). México se posicionará como una potencia turística a nivel global con una oferta diversificada de servicios y destinos competitivos. La actividad turística detonará la inversión y el crecimiento económico, impulsando el desarrollo regional equilibrado y los beneficios sociales del país.

\section{Desarrollo Turístico}

Al contribuir con cerca del nueve por ciento del PIB nacional, el turismo es una actividad económica crucial para el desarrollo de México. Es de destacar que esta participación se conserva más o menos constante en el tiempo. (Madrid, 2015)16. De igual manera su aporte en materia de empleo es uno de los más transcendental, pues genera 2.4 millones de puestos de trabajo. El turismo combate la pobreza, la marginación y la desigualdad de la única manera racional y sostenible que puede ser esta lucha, es decir, generando riqueza. En 2010, el $45 \%$ de los municipios del país tenían un rezago social medio, alto y muy alto; por otro lado, en los 233 municipios turísticos del país, el rezago era solo del $10.8 \%$. El turismo se ha configurado como uno de los motores económicos más importantes de la segunda mitad del siglo xx. Su incidencia en la encomia es directa sobre las empresas turísticas (alojamientos hoteleros y extra hoteleros, establecimientos de restauración, agencias de viajes, transportes,...) - e indirecta - difícil de evaluar y determinar su impacto sobre el resto de los sectores económicos. (Martín, 2010)17. En conceptualización de crecimiento económico y desarrollo económico el primero como el aumento de la producción real de bienes y servicios per cápita de un país. Ello implica que la economía se produce más bienes y servicios para satisfacer los deseos materiales de la población. Es un proceso sostenido a largo tiempo en el que los niveles de actividad económica aumentan constantemente y se detecta, generalmente, a través de la evolución del producto nacional bruto (PNB) o del producto interior bruto (PIB) a largo plazo, medidas estadísticas del cambio de la producción de un país y, por tanto, de su nivel de actividad (Martín, 2010 en Lickorish, 2000). El crecimiento económico es un aspecto de otro proceso más general: el desarrollo de una sociedad. La evolución de cualquier sociedad a lo largo del tiempo refleja cambios fundamentales en su organización y en sus instituciones. Con el estudio del crecimiento económico solo se pretende analizar una parte de ese desarrollo social, aquella referente a la evolución de la producción y la riqueza de un país. El desarrollo económico es un concepto con muchos significados. Comúnmente se concibe como un mediador del progreso económico intenta analizar cómo se ha utilizado el crecimiento económico para mejorar los niveles de vida y el bienestar general de los habitantes de un país. En una interpretación más amplia se refiere a la transformación de las estructuras demográficas, económicas y sociales que acompañan al crecimiento y permiten la mejora en las condiciones socioeconómicas del conjunto de la población (mejoras en la provisión de servicios de salud, educación, infraestructuras y otros similares). Generalmente se mide a través de los indicadores del "índice de 
desarrollo humano" que elabora y publica anualmente Naciones Unidas, y el coeficiente de Gini que muestra los desequilibrios en la distribución de los ingresos en una población.

\section{Comonfort - Guanajuato}

El municipio de Comonfort se ubica a los $100^{\circ} 36^{\prime} 36^{\prime \prime}$ y $100^{\circ} 58^{\prime} 30^{\prime \prime}$ de longitud y $20^{\circ} 37^{\prime} 36^{\prime \prime}$ y $20^{\circ} 42^{\prime} 48^{\prime \prime}$ os $100^{\circ} 46^{\prime}$ de longitud oeste, a una altitud de 1,790 metros sobre nivel del mar (msnm). Con una superficie total de $485.4 \mathrm{~km} 2$, equivalente al $1.6 \%$ de la superficie estatal. Colinda al norte con el municipio de San Miguel de Allende; al este con los municipios de San Miguel de Allende y Apaseo el Grande; al sur con los municipios de Celaya y Santa Cruz de Juventino Rosas; al oeste con los municipios de Santa Cruz de Juventino Rosas y San Miguel de Allende. El municipio tiene una ubicación geográfica tan importante como activa. Basta observar sus colindancias para darse cuenta que, ocupa el $1.6 \%$ de la superficie del estado, podría permitirle a Comonfort ingresar a dos alternativas: al corredor industrial del Bajío por la ubicación con Celaya, y al corredor turístico por su cercanía con San Miguel de Allende.

Figura $\mathrm{N}^{\circ}$ 1. Ubicación de Comonfort Guanaiuato.

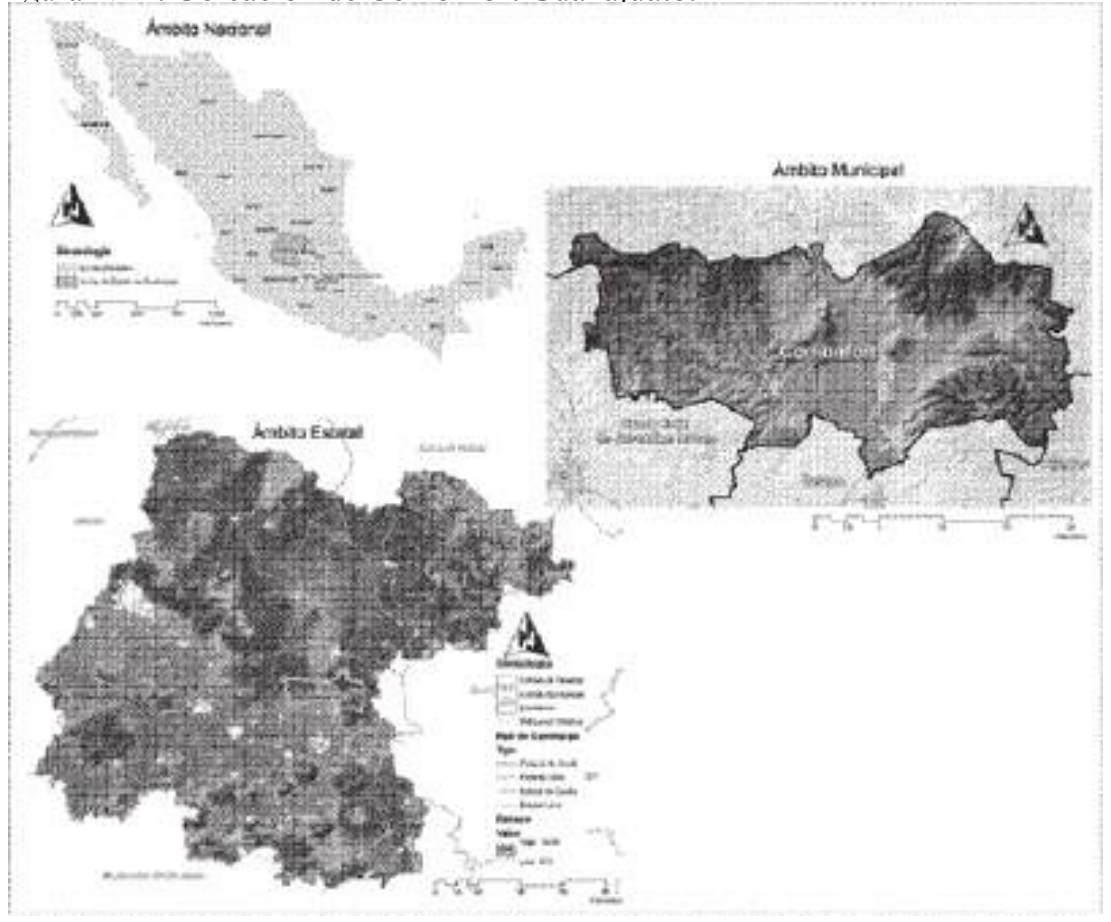


Fuente: (Méndez, 2016 en Cartografía base IPLANEG/INEGI 2010).

Sus principales vías de acceso son los transportes ferroviarios y la carretera, oficialmente según el INEGI, tiene 153 poblaciones o lugares de vivienda aunque solo 84 lugares son considerados como ranchos o poblaciones pues muchas de ellas son granjas, terrenos, o ranchos particulares donde vive una familia o el encargado, otras son comunidades pequeñas con pocos habitantes (Franco, 2015).

El territorio del estado de Guanajuato, presenta una diversidad en las condiciones territoriales que han suscitado la clasificación de cuatro regiones geográficas, que facilitan la planeación, estas a su vez se han dividido en diez subregiones generadas de manera estratégica para la planeación regional y sectorial que contemplan el sistema estatal de planeación. La subdivisión de estas regiones está adaptada a las características económicas, sociales, culturales y naturales que de manera homogénea distinguen a cada una. El municipio de Comonfort pertenece a la subregión denominada Zona Metropolitana Laja-Bajío la cual es la más extensa en porcentaje territorial de la región III con un $10.6 \%$ del total del territorio estatal; lo conforman nueve municipios: Apaseo el Alto, Apaseo el Grande, Celaya, Comonfort, Cortázar, Jaral del Progreso, Santa Cruz de Juventino Rosas, Tarimoro y Villagrán. (Méndez, 2016). La superficie local del territorio de Comonfort corresponde al $6.24 \%$ de la Región centro y representa el $15.0 \%$ del territorio de la subregión 7. El municipio tiene comunicación a través de la carretera 51 al norte de los municipios de Dolores Hidalgo, Guanajuato y San Miguel de Allende, y hacia el sur el municipio de Celaya. Las características del patrimonio cultural tanto tangible como intangible, dan un claro reflejo de la importancia a nivel subregional del municipio, por la prevalencia a buscar sinónimos de estos elementos. Además, ha tenido mayor auge gracias a la influencia turística que tiene la ciudad de San Miguel de Allende, ubicada al norte del municipio, dentro de la región 4 . En cuanto al entorno natural Comonfort es uno de los municipios de la subregión que conserva un amplio territorio de ecosistema natural; en su mayoría el municipio presenta una fisonomía montañosa, que se genera por la sierra de las Codornices, que es una condición diferente a la gran parte de la región de la Zona Laja Bajío; las áreas de cultivo también son parte del paisaje natural que se presenta en cuanto se ingresa al territorio municipal.

\section{Pueblos y Barrios de Comonfort}

Para efectos de la creación del catálogo cultural como detonador de turismo cultural para la ciudad Comonfort se han revisado los principales barrios y pueblos con los que cuenta la ciudad (ver imagen 2), de acuerdo a (Franco, 2016), para hacer un previo recogido de información se han descrito a continuación para generalizar el campo de estudio. 
Figura $\mathrm{N}^{\circ}$ 2. Plano de las comunidades de Comonfort Guanajuato

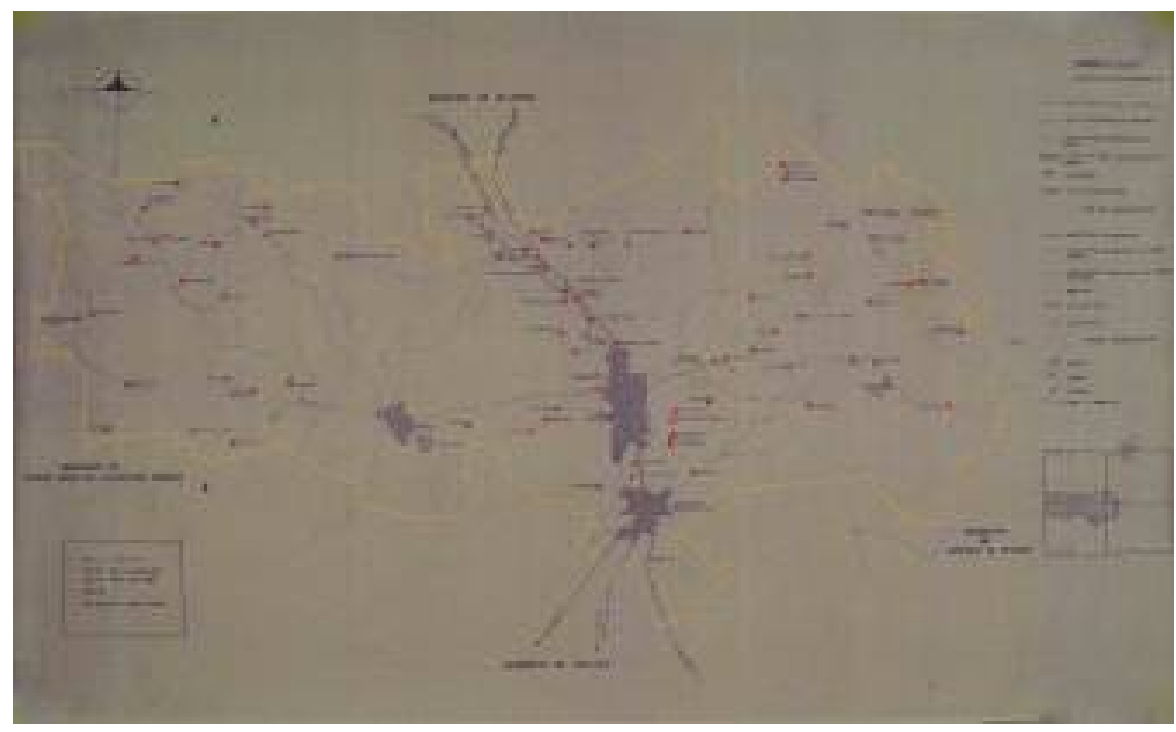

Fuente: (Carracedo, 2016 en Sánchez).

Barrios y pueblos a considerar en el presente trabajo de investigación:

Camacho; Aquí se establecieron los primeros españoles y fueron también los otomíes procedentes de Jilotepec, los primeros que formaron allí una población con calles y capillas, asimismo también son los descendientes de aquellos, los que, a golpe de cincel, crean con sus manos los útiles molcajetes, hechos con la piedra de los cerros.

Barrio de la Palma; Fundado en 1761 con gentes del barrio de San Agustín, aquí se honra a la Santa Cruz que trajeron de la hacienda del molino de Soria, le nombraron "la palma" por la razón de que en medio del pueblo había una palmera muy grande. El motivo de habitarse fue con la intención de fincar la capilla para honrar a la Santa Cruz.

Barrio de la Candelaria; Se funda el primero de mayo de 1809, en su capilla se venera la virgen del mismo nombre, y en su fiesta el dos de febrero es el día indicado para bendecir imágenes del niño dios y las semillas que se ocuparan en las siembras.

Barrio de Montecillo; Lugar antiguo donde los caciques otomíes pusieron orden, En 
su capilla se venera al santo Ecce Homo, a quien se le imploran remedios para el mal de amor, veneración que ha sufrido alteración en el modo en el que se interpreta a través de los años, pues siendo las palabras que pronuncio Pilatos al presentar a nuestro señor Jesucristo a los judíos.

Barrio de los Remedios; Guarda las tradiciones de los antiguos, trae el sonido rítmico del teponaztle y tamborcillos de mano, mezclados con el canto graves del caracol, y con esto da inicio a la fiesta grande del pueblo, la fiesta de la virgen que quiso quedarse en chamacuero, pues Comonfort tiene un solo patrocinio, el de San Francisco, pero una fiesta o feria grande, la de la Virgen de los Remedios.

Barrio de la Rinconada; En su pueblo se encuentra la santa cruz de mezquite a la que según la tradición milagrosamente le broto un retoño verde, su fiesta es el 03 de mayo se honra con danzas, coloquios y festividades alegres.

Barrio de San Agustín; Empezó su existencia como un sitio que establecieron los españoles para la cría de ganado y cultivo.

Empalme Escobedo; En el año de 2003 Empalme Escobedo celebro sus primeros cien años junto con su fiesta patronal del veinticuatro de mayo, este pueblo tuvo origen juntamente con la creación de la estación ferrocarrilera hacia finales del siglo diez y nueve, cuando el ferrocarril progresaba rápidamente, pues desde mil ochocientos setenta hubo las primeras líneas en el estado, el primer tren que paso por lo que ahora es empalme fue en 1888, en aquel entonces era llamado camino de fierro mexicano. Su ruta era de la ciudad de México a Nuevo Laredo, pasando por Toluca, Acambaro, Celaya y Comonfort, una de las etapas era de San Luís Potosí a San Miguel de allende, en San Miguel se hacía cambio de máquinas y tripulantes para proseguir a la siguiente etapa en Acambaro.

Rancho de Landin; La antigua hacienda de cañadas de Landin fue establecida en 1632, cuando Don Pedro de Landin le comprara al regidor de Celaya y depositario General de su Majestad, don Cristóbal cano y Molina, (Molinillos, le dicen otros) unas caballerías de monte y labor para establecer una estancia para criar ganado.

Rancho de las Palmillas de San Juan; Este pintoresco rancho, anteriormente fue una hacienda llamada palmillas, o las palmillas, ya que así aparece consignado en documentos antiguos, aunque con la aclaración de que existen en el municipio dos poblaciones con el mismo nombre, una llamada palmillas del picacho, y la otra llamada palmillas de San Juan.

Hacienda la Cantera, y Rancho Vallejito; En 1890 la hacienda de la Cantera constaba de diez y seis caballerías y setenta y dos centésimos, disfrutando cinco días de agua del arroyo de Neutla cada veinte días. 
Pueblo de Jalpilla; La antigua hacienda de Jalpilla actualmente convertida en un gran pueblo, fue fundado el 27 de abril de 1552, tuvo su origen como una estancia o sitio que establecieron los españoles para criar ganado, y es tan antiguo como Chamacuero.

Soria; El hermoso y turístico pueblo de Soria tiene siglos de existencia, anteriormente fue una enrome hacienda conocida como el molino.

Rancho de Dondiego; Este rancho primeramente fue una hacienda llamada hacienda de San Luis Obispo, Se llamó hacienda de cañadas de Dondiego, y fue una de las grandes, se llamó también hacienda de cañadas de Dondiego, y fue una de las más grandes, pues originalmente tenía 4,855-12-68. Hectáreas.

Neutla; Fue un pueblo prehispánico habitado o fundado primeramente por gentes de Lengua Náhuatl y a la llegada de los conquistadores españoles a ese lugar, fue conocido con el nombre de Santiago de Neutla, y su probable fundador fue Francisco Pérez.

Orduña; Este pueblo que anteriormente fuera una antigua hacienda a través de los siglos, se ha conocido con los siguientes nombres; San Nicolás Tolentino, lo de porcel, la Lope, o la barranca de Lope, San Nicolás de Orduña y ahora solo Orduña.

Rancho de delgado y Ranchito de delgado; Hasta hace poco así llamaban a estas dos poblaciones, pero últimamente los nombraron Delgado de arriba y Delgado de abajo.

Rancho la Laguna; La antigua hacienda de la Laguna probablemente fue fundada en 1660, pues había una cantera gravada, que estaba colocada en un muro de la hacienda y tenía escrita la primera estrofa del canto del alabado y en seguida la citada fecha.

El picacho; Este poblado que anteriormente fuera una hacienda en 1552 tiene un templo muy antiguo, se nota en mal estado ya que se le han hecho algunas cuarteaduras, se ha optado por repararlo, ya que se considera una autentica reliquia, ahí se venera a la Santa Cruz.

Rancho la Asunción; El rancho de la asunción se formó en 1950, cuando algunas familias de ejidatarios se fueron a vivir a ese lugar, el nombre de Asunción, "se lo puso el padre Jesucristo" decía un habitante de allí, pues no tenía ninguno. (Este se refería al párroco de Neutla Jesús Juárez).

Las Pomas; Se dice que, en tiempos de la revolución, en la pomas vivían unos individuos que robaban y ocultaban en su rancho el producto de los huertos, el rancho quedo abandonado hasta el año de mil novecientos cincuenta, en que se pobló nuevamente por personas procedentes de otros ranchos que se fueron a vivir allí, encontrando los restos 
de las casas antiguas, y con una buena suerte se puede encontrar el dinero que enterraban los que vivieron antes.

EI Puertecito; Se le nombra puerto a una forma de terreno bajo situado entre dos alturas medianas, y el puertecito que precisamente tiene esa forma se pobló el primero de noviembre de mil novecientos cincuenta y cuatro, cuando la familia de don Ventura Sánchez se fue a vivir en esos terrenos, al poco tiempo llegaron más familias y se formando el rancho con la descendencia de estas personas.

Hacienda de Carrera; Esta hacienda se localiza muy cerca del pueblo de Neutla, a tan solo unos dos kilómetros de distancia, después de mucho tiempo la hacienda estuvo pues los propietarios no quisieran saber nada de ella y por vándalos fue destruida y robada hasta que una persona de Neutla la rescato comprándola al grupo de individuos que se la habían repartido en lotes, y con mucho esfuerzo la reconstruyo respetando su estilo original.

\section{DESARROLLO Y RESULTADOS}

El Patrimonio se refiere al conjunto de bienes heredados que se viven en el presente y que deben ser protegidos y conservados, para ser transmitidos a las futuras generaciones a su vez el Patrimonio Mundial está integrado por bienes o sitios que poseen un valor universal excepcional, es decir, que tienen una importancia cultural o natural extraordinaria, que trascienden fronteras y tienen un significado especial dentro de la historia de la humanidad. Su desaparición sería una pérdida irreparable para la humanidad. (UNAM, 2015), estos serán los que nos forjen identidad y comprensión del presente a través de nuestro pasado. El turismo que nos dice es un fenómeno social, cultural y económico relacionado con el movimiento de las personas a lugares que se encuentran fuera de su lugar de residencia habitual por motivos personales o de negocios/profesionales. Estas personas se denominan visitantes (que pueden ser turistas o excursionistas; residentes o no residentes) y el turismo tiene que ver con sus actividades, de las cuales algunas implican un gasto turístico. (OMT, 2015). Derivado el Turismo Cultural es "aquel viaje turístico motivado por conocer, comprender y disfrutar el conjunto de rasgos y elementos distintivos, espirituales y materiales, intelectuales y afectivos que caracterizan a una sociedad o grupo social de un destino específico". (CESTUR, 2015). "Todo desplazamiento turístico tiene una implicación cultural: sin la cultura no se explica el turismo".

El turismo es un hecho de la cultura e implica la interacción entre grupos sociales. A través del ejercicio del turismo se pueden conocer sitios e intercambiar saberes y experiencias. Es un camino para la valoración del patrimonio cultural de cada pueblo, para el diálogo entre culturas y para el desarrollo de las comunidades. (CONACULTA, 2015). Por consiguiente 
el turismo genera otros conceptos interesantes para nuestro análisis, uno es la demanda turística que la componen los visitantes (que incluyen turistas y excursionistas), y se ve afectada por factores internos a la demanda, como las motivaciones que animan a viajar; externos, como las mejoras económicas, los cambios demográficos y sociales. Y la oferta turística está integrada por los elementos que atraen al turista a un destino determinado y satisfacen todas sus necesidades. (OMT, 2015).

Tabla N¹ Activos Materiales

\begin{tabular}{|l|l|}
\hline \multicolumn{1}{|c|}{ Activo } & \multicolumn{1}{c|}{ Descripción } \\
\hline $\begin{array}{l}\text { Templo de San Fran- } \\
\text { cisco }\end{array}$ & $\begin{array}{l}\text { El templo de San Francisco, se comenzó a edificar en 1592 } \\
\text { y su construcción duró 34 años y fue puesto al culto en 1626 } \\
\text { con la aprobación del excelentísimo fray Alonso de Guerra, } \\
\text { cuenta con adornos laterales con influencia del churrigue- } \\
\text { resco en madera dorada, cuenta con una colección de cua- } \\
\text { dros al óleo colocados por don Ignacio Basurto. En 1898 se } \\
\text { terminó la construcción del Altar Mayor. Este templo es una } \\
\\
\text { auténtica pinacoteca con obra de extraordinarios pintores } \\
\text { como el español Murillo y los mexicanos Cabrera y Juárez. }\end{array}$ \\
\hline
\end{tabular}

Imágenes 1, 2 y 3. Templo de San Francisco
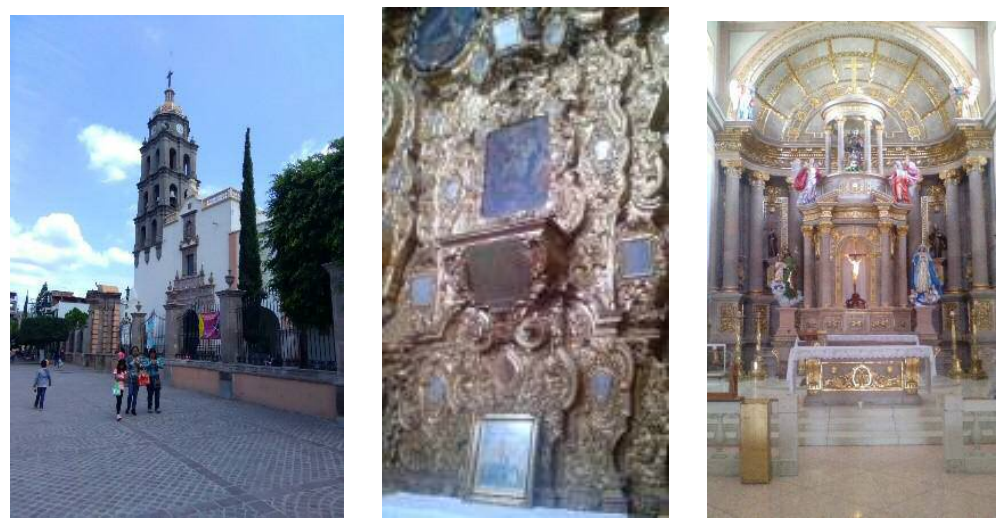

Fuente: Elaboración Propia 


\begin{tabular}{|l|l|}
\hline Templo de los & $\begin{array}{l}\text { El templo de la Virgen de los Remedios quedó asentado en la } \\
\text { zona indígena, para lo cual los mismos habitantes de ese enton- } \\
\text { ces, participaron en la construcción del templo con piedras de } \\
\text { su misma casa, para convertir la casa de la familia en casa de } \\
\text { Dios. Se cuenta que en esta zona indígena se encontró a la ima- } \\
\text { gen de la Virgen en un maguey, y el dueño de las tierras, donó un } \\
\text { terreno, pero fue tanta la fe y veneración que la gente no cabía. }\end{array}$ \\
\hline $\begin{array}{l}\text { Templo de san } \\
\text { Antonio }\end{array}$ & $\begin{array}{l}\text { Si se vive en las proximidades del jardín principal de Comon- } \\
\text { fort, cada 13 de junio habrán de esperarse los compases de } \\
\text { una banda de viento, como parte de los festejos al Señor San }\end{array}$ \\
$\begin{array}{l}\text { Antonio en su día, lo cual, lejos de ser una molestia es todo } \\
\text { un privilegio, no cualquiera puede darse el lujo de acudir a } \\
\text { escuchar, con el agradable fresco de las ocho de la mañana, } \\
\text { los compases de la música de la banda de viento tradicional. } \\
\text { Sólo basta ser sensible para entender que esto es un privilegio. } \\
\text { Algo que nos puede dar una idea de la antigüedad del tem- } \\
\text { plo es que la alineación del mismo está girada casi 20 con } \\
\text { respecto al trazo de la calle, lo cual sugiere que fue des- } \\
\text { plantado mucho antes de que se marcara el trazo defini- } \\
\text { tivo de la calle o de la plaza. Curiosamente, su alineación } \\
\text { coincide con el paramento de la plaza en el costado sur. }\end{array}$ \\
\hline $\begin{array}{l}\text { Santuario de } \\
\text { Guadalupe }\end{array}$ & $\begin{array}{l}\text { En 1667, el papa clemente IX emitió una bula pontificia ins- } \\
\text { tituyendo el doce de diciembre como día dedicado a la virgen } \\
\text { de Guadalupe, y tiempo después el rey de España autorizo al } \\
\text { Virrey de la nueva para celebrarse las fiestas en honor a la } \\
\text { virgen de Guadalupe, se construyeron altares, santuarios y } \\
\text { templos en todas las partes de la república, en chamacuero } \\
\text { que desde su origen como pueblo cristiano siempre ha sido } \\
\text { mariano, como lo prueba la gran devoción que se le profesa a } \\
\text { la virgen de los remedios, no podía quedar fuera de esta disi- } \\
\text { pación y no solo le dedicaron un altar en el templo, sino que } \\
\text { también le edificaron su santuario en la calle que da al rio, y el } \\
\text { lugar se conoció como barrio de Guadalupe, (Franco, 2016). }\end{array}$ \\
\hline
\end{tabular}




\begin{tabular}{|l|l|}
\hline $\begin{array}{l}\text { Antigua esta- } \\
\text { ción del tren }\end{array}$ & $\begin{array}{l}\text { Don Eusebio González que se nombra como importante en } \\
\text { la descripción del poblado de Soria, estaba en tratos con don } \\
\text { Lucas Alamán, quien tenía por esos momentos unos telares } \\
\text { ingleses en la fábrica de Textiles Cempoala en Celaya, ubi- } \\
\text { cada en la calle 5 de mayo. Una vez hecha la compra don } \\
\text { Eusebio instala a un costado del Molino dichos telares, de } \\
\text { esta manera da impulso a otra industria que viene a reforzar } \\
\text { la molienda de trigo. De esta manera es muy posible que el } \\
\text { transporte fuera originalmente a lomo de bestia, pero se dice } \\
\text { que ya en 1888 había línea de ferrocarril funcionando hasta } \\
\text { El Molino, lugar que ya había cambiado de nombre por el de } \\
\text { Soria". Por aquellos años, el mayor cliente que tenía el Fe- } \\
\text { rrocarril Central era el Molino, la estación se construyó a es- } \\
\text { paldas de ésta fábrica. Más adelante don Eusebio regala las } \\
\text { tierras para que se tiren las vías del nuevo ferrocarril, de allí } \\
\text { que surge la tradición de llamarle Empalme de González, esto } \\
\text { sucedía a principios del siglo XX, es en 1903 cuando se inicia } \\
\text { el tendido de vías para el servicio de la ruta México - Queré- } \\
\text { taro - Escobedo - San Luís - Laredo con la innovación de la } \\
\text { vía ancha. Es para 1905 cuando la línea ya llegaba a Empal- } \\
\text { me. Ya para 1948, Ferrocarriles Nacionales de México hace } \\
\text { una gran inversión, inicia la modernización de los talleres del } \\
\text { empalme ferrocarrilero, eran los tiempos de Miguel Alemán, } \\
\text { los tendidos de vías corrían por varios kilómetros al norte y } \\
\text { la cantidad de vagones que hacían fila para ser reparados en } \\
\text { momentos llegaba insuficiente (Arredondo, 2010 en Chávez). }\end{array}$ \\
\hline
\end{tabular}




\begin{tabular}{|l|l|}
\hline $\begin{array}{l}\text { Plaza cívica Dr. } \\
\text { Mora }\end{array}$ & $\begin{array}{l}\text { Esta plaza comprende el espacio de frente al } \\
\text { templo de San Francisco y el lateral al de mer- } \\
\text { cado municipal, se puede recorrer o disfru- } \\
\text { tar de la vista además de que se adecua como } \\
\text { plaza para eventos y cuestiones protocolarias. }\end{array}$ \\
\hline $\begin{array}{l}\text { Monumento a Igna- } \\
\text { cio Comonfort }\end{array}$ & $\begin{array}{l}\text { Cerca de San Juan de la Vega, Guanajuato. Méxi- } \\
\text { co, donde aún se conserva el monumento (malas } \\
\text { condiciones) que se erigió para recordar el sitio } \\
\text { donde cayó herido de muerte sobre el viejo ca- } \\
\text { mino real. En el poblado de Soria, hacienda el } \\
\text { Molino es donde se encuentra el monumento si } \\
\text { tener mucha información este fue el lugar don- } \\
\text { de murió Ignacio Comonfort pobladores de Soria } \\
\text { lo han integrado a un mapa turístico que se mues- } \\
\text { tra en apéndice este está al intemperie entre sem- } \\
\text { bradíos y ha sido maltratado por las condiciones } \\
\text { del clima y habitantes lo conocen como la cruz. }\end{array}$ \\
\hline
\end{tabular}

Figura $\mathrm{N}^{\circ} 4$ y 5 . Monumento a Ignacio Comonfort

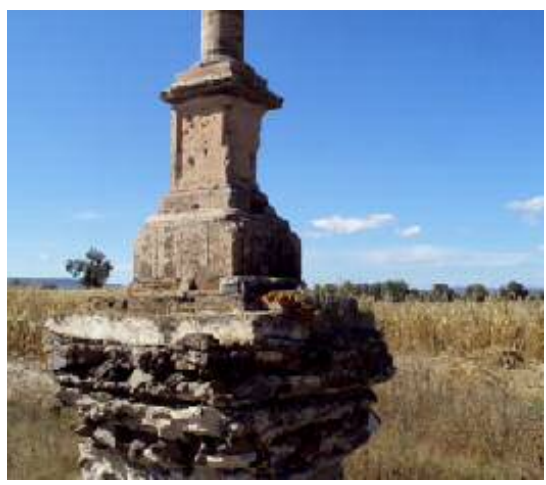

Fuente: (Arredondo, 2010).

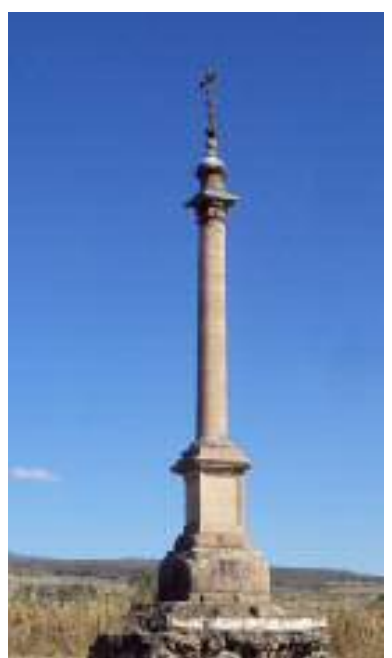




\begin{tabular}{|l|l|}
\hline Piedra de & $\begin{array}{l}\text { Lo que identifica a nivel nacional al municipio de Comonfort es la talla } \\
\text { de piedra volcánica para molcajetes. El arte de elaborar un buen molcaje- } \\
\text { te no se limita al aspecto estético, la forma y el diseño deben permitir que } \\
\text { se puedan macerar los ingredientes que en él se depositen, por lo mismo, } \\
\text { la selección de la piedra intervendrá en el resultado final, los maestros } \\
\text { labradores de la región saben seleccionar las piedras de las que puede } \\
\text { salir un artefacto no sólo bien formado sino con la textura apropiada } \\
\text { para la molienda. La piedra "de molcajete" es dura y densa, tiene además } \\
\text { una textura porosa, idónea para que los chiles, los jitomates, la cebolla y } \\
\text { demás invitados a la salsa se homogenicen en la medida exacta y superen } \\
\text {-según lo afirma al 99.99\% de los mexicanos-. En el cerro de Los Reme- } \\
\text { dios hay una cierta abundancia de esta piedra, por ello, desde hace varias } \\
\text { centurias, se extrae de manera lenta pero constante, por esta misma ra- } \\
\text { zón, la falda sur poniente del cerro es lugar de asiento para varios talleres } \\
\text { de fabricación de molcajetes. La materia prima se extrae con la ayuda de } \\
\text { barras y barretas, a veces se detona pólvora y el consenso de los artesanos } \\
\text { es que cada día cuesta más trabajo localizar las vetas apropiadas. Hace } \\
\text { un par de años las minas tradicionalmente explotadas fueron cerradas } \\
\text { por estar en terrenos de la zona arqueológica de los remedios, en estos } \\
\text { momentos la piedra de molcajete se extrae de otra porción del cerro. } \\
\text { Aunque muchas personas adquieren estos utensilios con fines meramente } \\
\text { ornamentales, ello no implica que se fabriquen molcajetes "de utilería", } \\
\text { todos tienen la forma y las propiedades necesarias para la molienda. El ar- } \\
\text { tesano no puede saber si su producto será empleado en la cocina o servirá } \\
\text { sólo como adorno. Para la fabricación se utiliza una herramienta llamada } \\
\text { picadera, una especie de martillo puntiagudo con mango de membrillo. } \\
\text { Enestazonadelaciudadseescuchacotidianamenteelacompasadomartilleo } \\
\text { de"lamáquina"sobrelapiedra,golpetrasgolpeenun ritmolentoymeditado. }\end{array}$ \\
\hline
\end{tabular}


Imagen 6. Piedra de Molcajete. Imagen 7. Proceso de Picado de Molcajete.

Imagen 8. Molcajetes Terminados.
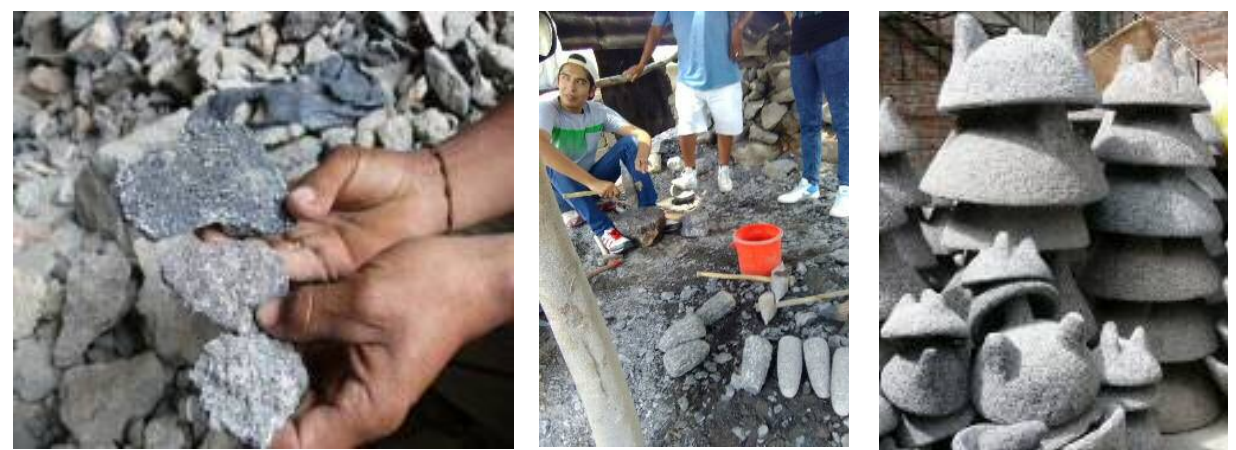

Fuente: (Carracedo, 2016). Fuente: Elaboración propia. Fuente: (Carracedo, 2016).

\begin{tabular}{|l|l|}
\hline Carrizo & $\begin{array}{l}\text { En las riberas del río Laja prolifera una especie de caña silvestre que } \\
\text { llamamos carrizo, la presencia de esta planta es constante a lo largo } \\
\text { del año, por lo que obtener la materia prima para realizar objetos } \\
\text { de carrizo es una labor que puede realizarse en cualquier tempo- } \\
\text { rada. Sin embargo, la caña no puede almacenarse indefinidamente, } \\
\text { de hecho, el carrizo debe cortarse verde y manufacturarse casi de } \\
\text { inmediato antes de que pierda su flexibilidad, por lo mismo suele } \\
\text { trabajarse en un ambiente húmedo y oscuro, ya que el calor des- } \\
\text { hidrata las fibras vegetales. En la comunidad (Orduña de abajo) } \\
\text { hay muchas personas se dedican a esta actividad. Pero sus manos } \\
\text { cada vez tejen menos carrizo y no es que hayan perdido facultades, } \\
\text { simplemente gana un salario más digno dedicándose a otras labores. }\end{array}$ \\
\hline
\end{tabular}

Imagen 9. Artículos de Cestería

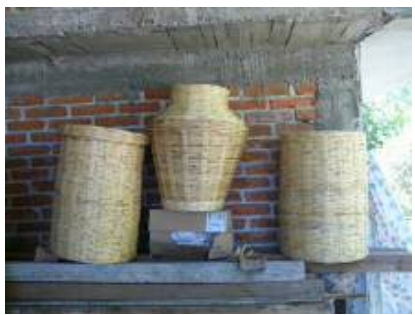

Fuente: (Carracedo, 2016). 


\begin{tabular}{|l|l|l|}
\hline Bronce y Alu- & Hace unos treinta y cinco años, el señor Anto- \\
minio & nio Hernández Lindero estableció la primera fun- \\
& didora artesanal de Comonfort. Labor nada simple \\
& que amerita un conocimiento sólido sobre este arte. \\
\hline
\end{tabular}

Imagen 10. Artesanías en bronce

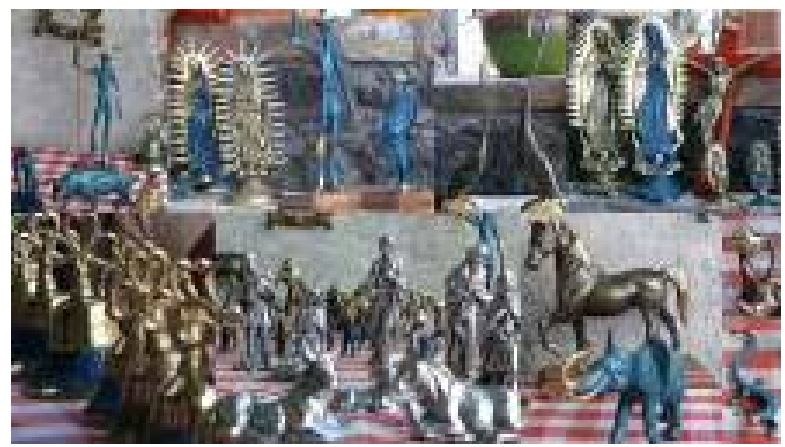

Fuente: (Carracedo, 2016).

\begin{tabular}{|l|l|}
\hline Cerámica & $\begin{array}{l}\text { La técnica de solidificar el barro y la arcilla mediante el ca- } \\
\text { lor es universal y muy antigua, prácticamente no hay cultu- } \\
\text { ra ni grupo humano que no tengan tradiciones al respecto. } \\
\text { En Comonfort, por alguna circunstancia, solamente existe } \\
\text { un taller dedicado a la fabricación de objetos de cerámica. }\end{array}$ \\
\hline
\end{tabular}

Imagen 11. Artículos de cerámica

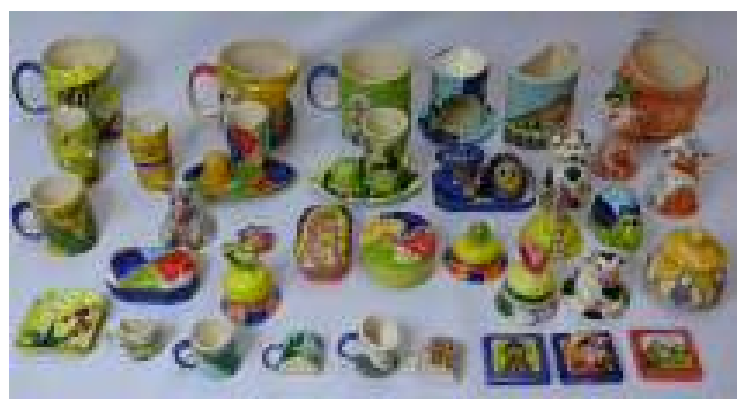

Fuente: (Carracedo, 2016). 


\begin{tabular}{|l|l|}
\hline $\begin{array}{l}\text { Sellos para } \\
\text { estampar tor- } \\
\text { tillas }\end{array}$ & $\begin{array}{l}\text { Las tortillas hechas a mano son casi una artesanía, baste con } \\
\text { valorar el trabajo que hay de por medio en su elaboración y el } \\
\text { regocijo que su aroma y su sabor producen en nuestros senti- } \\
\text { dos. Como si esto no bastara, algunas afanosas mujeres se dan } \\
\text { a la tarea de estampar sus tortillas para hacerlas más atractivas } \\
\text { a la vista. La artesanía en cuestión son los sellos para estampar } \\
\text { las tortillas, no las tortillas en sí. Dado que la existencia de la } \\
\text { tradición de estampar tortillas no es universalmente conocida, } \\
\text { nos detenemos a mencionar en qué consiste ese significativo } \\
\text { arte. Parte de las mujeres que ejercen este arte tienen ascen- } \\
\text { dencia Nah Nuh (otomí) la mujer que sabe hacer tortillas estam- } \\
\text { padas bellas y deliciosas tiene un mérito adicional, totalmente } \\
\text { independiente a sus características étnico culturales, en algunas } \\
\text { comunidades del municipio (Orduña, Morales, Delgado, La } \\
\text { Palma), se conserva este añejo arte. Para ocasiones especiales } \\
\text {-particularmente en las celebraciones de semana santa, pero } \\
\text { también en bodas y bautizos- algunas mujeres de la localidad } \\
\text { elaboran tortillas con bellos estampados. La técnica es sencilla } \\
\text { pero, evidentemente, laboriosa y requiere de la utilización de un } \\
\text { sello fabricado para este fin. El proceso de estampado es poco } \\
\text { frecuente y, además, los sellos prácticamente no se deterioran. }\end{array}$ \\
\hline
\end{tabular}

Fuente: Elementos tomados, enriquecidos y adecuados de (Carracedo, 2016).

Imagenes 12 y 13 . Sellos para tortillas
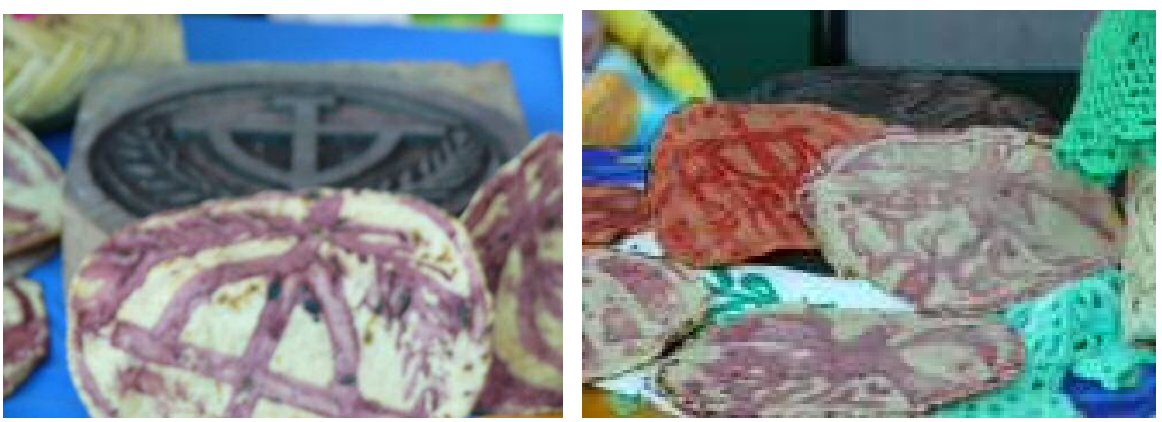
Tabla $\mathbf{N}^{\circ} 2$ Activos Inmateriales

\begin{tabular}{|c|c|}
\hline Activo & Descripción \\
\hline $\begin{array}{l}\text { Camino Real } \\
\text { u Nacional }\end{array}$ & $\begin{array}{l}\text { El camino real también llamado camino de la plata, y en al- } \\
\text { gunos documentos mencionado como camino nacional tiene } \\
\text { algunos tramos que pasan por las comunidades de Comon- } \\
\text { fort en Soria ha sido contemplado de los tours que ofrecen } \\
\text { las personas locales, este camino construido hace } 500 \text { años } \\
\text { constituyo el eje de comunicación para el transporte de mer- } \\
\text { cancías, ejércitos y otras actividades durante muchas años. }\end{array}$ \\
\hline $\begin{array}{l}\text { Fiesta a la } \\
\text { Santa Cruz }\end{array}$ & $\begin{array}{l}\text { Durante la festividad a la Santa Cruz el día } 3 \text { de mayo se ce- } \\
\text { lebra con misa, danza de locos, rezo de rosario en procesión, } \\
\text { quema de castillo pirotécnico, baile y convivencia. En este día } \\
\text { los muchachos de la comunidad piden pollos o limosna para } \\
\text { comprarlos que cuelgan en una canasta hasta donde llegan los } \\
\text { muchachos a caballo y tratan de bajar la canasta para ganarse un } \\
\text { pollo. Esta se ha registrado como la tradicional carrera de pollos. }\end{array}$ \\
\hline $\begin{array}{l}\text { Fiesta de la } \\
\text { Candelaria }\end{array}$ & $\begin{array}{l}\text { En la actualidad la fiesta conmemora la visita de la virgen } \\
\text { María al templo, cuarenta días después del nacimiento del } \\
\text { Niño Jesús, para cumplir con el ritual de purificación des- } \\
\text { pués del parto y de presentación del Infante. La purificación } \\
\text { está simbolizada con el fuego, de ahí el nombre de Candela- } \\
\text { ria y el simbolismo de las velas para esta celebración. Deben } \\
\text { invitarse tamales y no otro platillo, pues es una reminiscen- } \\
\text { cia de tiempos prehispánicos en que se consumían duran- } \\
\text { te diferentes rituales relacionados con los ciclos agrícolas. }\end{array}$ \\
\hline
\end{tabular}




\begin{tabular}{|c|c|}
\hline Carnaval & $\begin{array}{l}\text { Por extraño que parezca, la celebración lúdica, libertina y des- } \\
\text { enfrenada del carnaval está ligada al ritual cristiano de la cua- } \\
\text { resma. De hecho una proviene etimología de Carne-vale, la car- } \\
\text { ne que se va en alusión a la inminente cuaresma, el martes de } \\
\text { carnaval es el martes anterior al miércoles de ceniza con el que } \\
\text { da inicio la cuaresma que termina en el viernes santo. De alguna } \\
\text { manera se ve a la cuaresma como la última oportunidad para } \\
\text { el desenfreno de todo lo desenfrenable, justo antes de entrar } \\
\text { en el período de abstinencias de la cuaresma. En Comonfort el } \\
\text { desenfreno no es altamente notable y, además de algunos des- } \\
\text { files con creativos disfraces, por la noche del lunes y martes, } \\
\text { en algunas plazas los muchachos y los niños se persiguen para } \\
\text { romperse sobre la cabeza cascarones de huevos previamente } \\
\text { pintados y rellenados con confeti, harina o en algunos casos } \\
\text { diamantina, pintura vegetal, oro musivo o mistión de plátano. }\end{array}$ \\
\hline $\begin{array}{l}\text { Fiesta de } \\
\text { María Auxi- } \\
\text { liadora }\end{array}$ & $\begin{array}{l}\text { La fiesta en honor de la virgen María Auxiliadora tie- } \\
\text { ne muchos otros elementos que le dan singularidad y sig- } \\
\text { nificativo, en esta ocasión nos hemos referido (y muy } \\
\text { brevemente) a la peregrinación de los ferrocarrileros. }\end{array}$ \\
\hline $\begin{array}{l}\text { Fiesta de } \\
\text { San Antonio }\end{array}$ & $\begin{array}{l}\text { En esta fiesta, como en muchas manifestaciones tradicionales } \\
\text { de los pueblos, hay una serie de elementos que resulta fasci- } \\
\text { nante analizar y tratar de entender cómo fue que se integraron } \\
\text { a la celebración y desde hace cuánto tiempo. Pese a lo fasci- } \\
\text { nante, generalmente terminamos en suposiciones y conjeturas. }\end{array}$ \\
\hline $\begin{array}{l}\text { Fiesta de } \\
\text { Santiago } \\
\text { Apóstol }\end{array}$ & $\begin{array}{l}\text { La comunidad de Neutla se localiza al Poniente de Nues- } \\
\text { tro Municipio, por su número de habitantes es la tercera en } \\
\text { importancia. Tan antigua como la cabecera municipal, la } \\
\text { fiesta patronal de Neutla es la dedicada a Santiago Após- } \\
\text { tol y se lleva a cabo, lógicamente, el veinticinco de Julio. }\end{array}$ \\
\hline $\begin{array}{l}\text { Fiesta de los } \\
\text { remedios }\end{array}$ & $\begin{array}{l}\text { Primer Fiesta; En el lugar donde antiguamente había un cen- } \\
\text { tro ceremonial, los pobladores españoles, siguiendo la es- } \\
\text { trategia que tan buenos resultados les daba, decidieron cons- } \\
\text { truir una capilla, años después a mediados del siglo XVII, a } \\
\text { un lado de esa capilla original construyeron un templo de- } \\
\text { dicado a la advocación de María como Nuestra Señora de } \\
\text { Los Remedios. Se dice que esta advocación era muy ve- } \\
\text { nerada por los conquistadores españoles, lo cierto es que } \\
\text { hoy día sigue siendo muy venerada, no sólo por los habitan- } \\
\text { tes del municipio sino por los habitantes de toda la región. }\end{array}$ \\
\hline
\end{tabular}




\begin{tabular}{|l|l|}
\hline $\begin{array}{l}\text { Fiesta de } \\
\text { San Fran- } \\
\text { cisco }\end{array}$ & $\begin{array}{l}\text { San Francisco de Asís es el Santo Patrono de Comonfort, no } \\
\text { por nada se llamó durante un tiempo San Francisco de Cha- } \\
\text { macuero, después, por alguna razón y contraviniendo la volun- } \\
\text { tad popular le quitaron ambos nombres. Si bien en el municipio } \\
\text { existen cuatro parroquias, la más poblada es la de la Cabecera } \\
\text { Municipal. San Francisco de Asís fue un santo italiano naci- } \\
\text { do en el siglo XII, que vivió ejemplarmente y fundó la orden } \\
\text { Franciscana, una de las tres que junto con dominicos y agus- } \\
\text { tinos llegaron a evangelizar el nuevo mundo. Por ello no es } \\
\text { raro que fundaran o refundaran varias poblaciones en México. }\end{array}$ \\
\hline
\end{tabular}

Gastronomía

\begin{tabular}{|l|l|}
\hline \multicolumn{1}{|c|}{ Activo } & \multicolumn{1}{c|}{ Descripción } \\
\hline Gorditas & $\begin{array}{l}\text { El platillo típico mexicano adecuado a manera de chamacue- } \\
\text { ro Comonfort, estas se encuentran dentro del mercado del } \\
\text { municipio, son elaboradas a base de maíz están pueden } \\
\text { ser de migajas (carne de cerdo) o de queso blanco, además } \\
\text { de que se acompañan con algún guiso de elección a los que } \\
\text { se ofrecen, son doradas en aceite y tienen precios accesibles } \\
\text { para los comensales además de ser icono ya de la ciudad. }\end{array}$ \\
\hline Nieves & $\begin{array}{l}\text { Hace más de medio siglo el señor Francisco Téllez se dedicaba } \\
\text { a fabricar y vender raspados. Como evolución directa de su } \\
\text { habilidad para manejar el hielo y los sabores, comenzó a vender } \\
\text { nieve de limón, siempre de manera ambulante, primero a pie, } \\
\text { en una mano portaba el bote de nieve y en la otra los vasos y } \\
\text { los barquillos; después en un burrito, colocaba un bote de nie- } \\
\text { ve a cada lado del animal y así recorría las calles del pueblo. }\end{array}$ \\
\hline $\begin{array}{l}\text { Fruta de } \\
\text { Horno }\end{array}$ & $\begin{array}{l}\text { Allá por los años treinta, quizá un poco antes, el señor Isidro } \\
\text { Centeno se dedicó a hacer pan, un pan tan exquisito y deli- } \\
\text { cado que, ochenta y tantos años después, varias generaciones } \\
\text { de chamacuerenses lo han disfrutado y lo siguen comiendo. }\end{array}$ \\
\hline
\end{tabular}

Fuente: Elementos tomados, enriquecidos y adecuados de (Carracedo, 2016). 
Como resultado se han plasmado los principales elementos culturales e históricos que podrían potenciar el desarrollo del municipio en harás del turismo. Obtenemos veintidós elementos propuestos entre activos materiales, inmateriales, gastronomía y artesanías, Desde la parte imagen se pueden desarrollar estos elementos para que sean referenciados y estandarizados como elemento substancial.

Los elementos se obtuvieron del devenir histórico de los más de quince pueblos que componen el municipio creando un panorama completo para desarrollar el turismo cultural. Durante las visitas exploratorias se pudo observar elementos clave que podrían desarrollar al municipio si no bien como pueblo mágico, y sin abundar tanto en la metodología se han revisado la caracterización de la misma para generar esta idea de ser un pueblo con encanto ( programa donde se celebra la revalorización de los atributos, la recuperación de bellos paisajes, el rescate de la historia y la cultura de algunas comunidades, actualmente desarrollado en el estado de México), puesto que se debe desarrollar de acuerdo a los estándares que marca el programa.

Pudiendo ser un destino que ofrecería nuevas visiones en turismo local y regional deberá revisar los aspectos del modelo sustentable para apegar a los aspectos ambiental, social y económico para generar el crecimiento y desarrollo poblacional, siendo y pensando como una actividad que potenciaría el comercio local y otras actividades, observaciones que se obtuvieron en los sondeos hacia la comunidad.

El modelo competitividad y sostenibilidad del destino propuesto para este trabajo de Ritchie \& Crouch, 2003 marca estos micro entornos para lograr objetivos en materia sostenible se revisó únicamente el elemento "Recursos y Atractores" básicos, se tendrían que revisar los otros cuatro elementos para generar ideas más acertadas sobre el potencial de destino, hemos obtenido que en la parte de Cultura que se busca es un destino fuerte que se compone además de comunidades históricas y que puede ofrecer este tipo de línea turística, además de estar limitado por dos destinos fuertes como lo es San Miguel de Allende y Celaya, el primero meramente cultural y el siguiente en cuestión de turismo de negocios que siempre busca complementar los viajes de este tipo con productos culturales $\mathrm{u}$ atractivos para sus eventos, sin duda reiteramos la idea de Comonfort como destino en surgimiento.

Terminando con la aportación de la investigación se genera la idea de crear para estos municipios en crecimiento catálogos culturales que referencien los elementos y atractivos de esta forma se puede tener el compendio para toma de decisiones en cuestión de turismo, se plasman los elementos y se puede enriquecer la oferta turística, además de sacar a luz los datos, narraciones, vivencias y aportaciones de que la comunidad puede tener esta como principal desarrolladora de la actividad, el local generara estas aportaciones como 
primer momento para que se puedan crear los productos idóneos siempre sustentados y que generen desarrollo para el residente que se encuentra o requiere desarrollo.

\section{CONCLUSIONES Y RECOMENDACIONES}

Se pudo obtener información necesaria e importante para cumplir con elementos mencionados en el caso de estudio para generar un previo diagnóstico de destino catalogándolo como fuerte en cuestión histórica y cultural.

Se obtiene información sobre el local mediante sondeos y su percepción hacia la cultural del lugar y el turismo en general. El local conoce los activos culturales de la Ciudad de Comonfort aun no su integración a la planta turística, pero algunos habitantes han iniciado a crear rutas y pequeños productos en sus comunidades o que genera la idea de un desarrollo en harás de turismo rural y cultual.

Se pudo acceder a un Catálogo cultural de la ciudad, integrando algunos otros elementos para tener un antecedente para la toma de decisiones y generación de estrategias. De esto, se recomienda difundir los atractivos turísticos denominados en el catálogo para que local pueda tener conocimiento de los mismos, encaminado a la preservación y conservación, así como para reforzar la identidad de los locales por medio de este proceso y poder así planificar y desarrollar un destino turístico sustentable que cuenta con un patrimonio cultural importante y que además se considere su cuidado y preservación dentro del fenómeno turístico.

Integración de más gente Local, en las actividades turísticas. Se sugiere el desarrollo de productos para Neutla y Soria con visiones de sustentabilidad para atacar carencias y desarrollar los que ya se proponen, además de reducir migración mediante actividades de turismo.

La generación de rutas conjuntas en los poblados cercanos reforzando identidad y creando actividades vistosas para los visitantes, así como la su revaloración de sus costumbres y tradiciones a fin de poder desarrollar atractivos turísticos que contribuyan en el desarrollo sustentable de la actividad turística en dicho municipio. Se considera, además, que el municipio de acuerdo a sus características, puede ser considerado en un primer momento como un destino complementario o de visita, lo anterior, debido, aunque carece de infraestructura turística suficiente, si puede ser capaz como destino de atender a visitantes y además provocar la atracción de estos, debido al potencial cultural que posee. 


\section{BIBLIOGRAFÍA}

Amycos (2010). El turismo responsable. Me pregunto, ¿Qué es..., (11), 2.

Arredondo, B. (2010). La Parroquia de San Francisco de Asís en Comonfort, Gto. El Bable, Recuperado de http://vamonosalbable.blogspot.mx/2010/02/la-paroquia-de-sanfrancisco-de-asis-en.html

Blasco, A. (2011). Turismo y Transporte. Madrid: Síntesis.

Calvante, A. (2007). El concepto moderno de sustentabilidad. UAIS, Sustentabilidad. 100 (2).

Carracedo, D. M. (2016). Fotografías. Chamacuero, Gto. También llamado Comonfort. Recuperado de http://chamacueromexico.com/pagina/Fotografias.html

Chacón, M. (2010). El desarrollo comunitario. Innovación y Experiencias Educativas (29), 2.

CONACULTA. (2015). ¿Qué es cultura? ABC del patrimonio cultural y turismo, 11.

Diócesis, C. (2013). Festividad de Nuestra Señora de los Remedios. Parroquia de San Francisco de Asís Comonfort, Recuperado de http://parroquiacomonfort.blogspot. $\mathrm{mx} / 2013 / 09 /$ festividad-de-nuestra-sra.html

Franco, J. A. (2015). Molcajeteando la historia de Chamacuero. Comonfort: CACREP. Lisocka, B. (2015). Introducción de las actividades turísticas en las comunidades rurales. El papel del contexto social y cultura. En C. Velarde (coord.), Referentes teóricos del turismo alternativo, Enfoque en comunidades rurales (pp.101). México: Juan Pablos.

Madrid, F. (2015). Diagnóstico y oportunidades del turismo en México. Ciudad de México: Limusa.

Martín, P. y Sáez, A. (2010). Turismo y Desarrollo Económico. En C. Sáez (coord.), Estructura Económica del Turismo. (pp. 93). Madrid: Síntesis.

OMT, (2015). Organización Mundial de Turismo. Recuperado de http://media.unwto. org/es/content/entender-el-turismo-glosario-basico\#

OMT, (2015). El turismo. Recuperado de http://ficus.pntic.mec.es/ibus0001/servicios/ turismo.html\#

OMT, (2016). Día Mundial del Turismo. World Tourism Organization Network, 1-3. Recuperado de http://wtd.unwto.org/es/content/abouthostwtd2014

Pulido, J., y Palomo, S., (2010). Turismo y sostenibilidad. En C. Sáez (coord.), Estructura Económica del Turismo. (pp. 327). Madrid: Síntesis.

Ruiz, O. (2008). Turismo: Factor de Desarrollo y Competitividad en México. Centro de Estudios Sociales y de Opinión Pública (46), 1.

Saldaña, M. (2014). Cultura y Turismo. En C. Valenzuela (coord.), Imaginarios del paisaje y el turismo entre tradición y distintivos oficiales (pp.105-107). México: Juan Pablos.

SECTUR, (2016). Creció turismo en México a casi el doble de la tasa mundial: 
CPTM. Comunicado 113, 1-5. Recuperado de https://www.gob.mx/sectur/prensa/ crecioturismoenmexicoacasieldobledelatasamundialcptm

UNAM, (2008). Guía mínima para la elaboración de Planes de Desarrollo Institucional. Dirección General de Planeación, pp. 1-12.

UNAM, (2015). Universidad Autónoma de México. Recuperado de http://www. patrimoniomundial.unam.mx/pagina/es/57/que-significa-ser-patrimonio-mundial

Velarde, M., Maldonado, A., y Gómez, S., (2015). Turismo Alternativo, desarrollo regional y sustentabilidad.Velarde (coord.), Referentes teóricos del turismo alternativo, Enfoque en comunidades rurales (pp.24). México: Juan Pablos. 